\author{
Marzena NOWAK ${ }^{1}$ \\ Karol MAJEWSKI ${ }^{2}$ \\ Piotr CISEK ${ }^{3}$
}

\title{
PROJEKT STANOWISKA LABORATORYJNEGO DO WERYFIKACJI METODY WYZNACZENIA TRÓJWYMIAROWEGO NIEUSTALONEGO POLA TEMPERATUR W ELEMENTACH GRUBOŚCIENNYCH
}

\begin{abstract}
W artykule przedstawiono projekt stanowiska badawczego, służącego do weryfikacji metody wyznaczania trójwymiarowego nieustalonego pola temperatur w elementach grubościennych. Głównym elementem opisywanego układu jest płyta wykonana ze stali P235GH o wymiarach 800 x $800 \mathrm{~mm}$ i grubości $85 \mathrm{~mm}$. Nierównomierny rozkład temperatury po grubości badanego elementu zostanie osiągnięty poprzez proces ogrzewania i chłodzenia jego przeciwległych powierzchni. $\mathrm{W}$ ramach artykułu zaprezentowano projekt stanowiska badawczego wraz z jego wizualizacją 3D. Szczegółowo opisano projekt płyty wraz z rozmieszczeniem i poprowadzeniem termoelektrycznych mierników temperatury oraz budowę układu ogrzewania i chłodzenia.
\end{abstract}

Słowa kluczowe: metoda odwrotna krocząca, nieustalone pole temperatury, stanowisko badawcze, elementy grubościenne, przewodzenie ciepła

\section{Wstęp}

Wyznaczenie rozkładu temperatur $\mathrm{w}$ grubościennych elementach ciśnieniowych (tj kolektory parowe, walczaki) pozwala na określenie występujących w nich naprężeń termicznych. Umożliwia to zatem ocenę trwałości resztkowej urządzeń i instalacji energetycznych. Opracowana została metoda odwrotna krocząca pozwalająca na wyznaczanie temperatury na powierzchni elementu $\mathrm{w}$ przypadku gdy znana jest temperatura przeciwległej powierzchni oraz gęstość strumienia przekazywanego ciepła [1-3]. W celu weryfikacji opracowanej metodyki obliczeń zaprojektowane zostało stanowisko badawcze, którego głów-

\footnotetext{
${ }^{1}$ Marzena Nowak, Politechnika Krakowska im. T. Kościuszki, nowak@ mech.pk.edu.pl

${ }^{2}$ Karol Majewski, Politechnika Krakowska im. T. Kościuszki, kmajewski@ mech.pk.edu.pl

${ }^{3}$ Piotr Cisek, Politechnika Krakowska im. T. Kościuszki, cisekpiotr@mech.pk.edu.pl
} 
nym elementem jest grubościenna płyta stalowa. Poprzez pomiar temperatury płyty w kilkudziesięciu punktach na ogrzewanej powierzchni możliwe będzie odtworzenie pola temperatury płyty w całej jej objętości. Następnie, za pomocą zaprezentowanej metody, wyznaczony zostanie rozkład naprężeń w badanym elemencie grubościennym. Weryfikacja metody oparta zostanie o pomiar temperatury w kilku punktach wewnątrz ściany płyty i na powierzchni chłodzonej.

\section{Projekt stanowiska badawczego}

Centralną częścią stanowiska badawczego służącego do weryfikacji metody wyznaczania nieustalonego pola temperatur stanowi grubościenna płyta wykonana ze stali P235GH. Nieustalone pole temperatury badanej płyty podyktowane zostanie zamontowaniem po jednej stronie płyty płaskiej grzałki elektrycznej. Odbiór ciepła po drugiej stronie płyty odbywać się będzie poprzez omywanie jej strumieniem czynnika chłodzącego dostarczanego za pomocą specjalnie do tego celu zaprojektowanego układu dysz. W celu wyznaczenia pola temperatur po stronie ,zimnej” (chłodzonej) i ,gorącej” (ogrzewanej) zamontowane zostaną termoelektryczne czujniki temperatury. Poglądowy schemat stanowiska pomiarowego przedstawiono na rysunku 1.

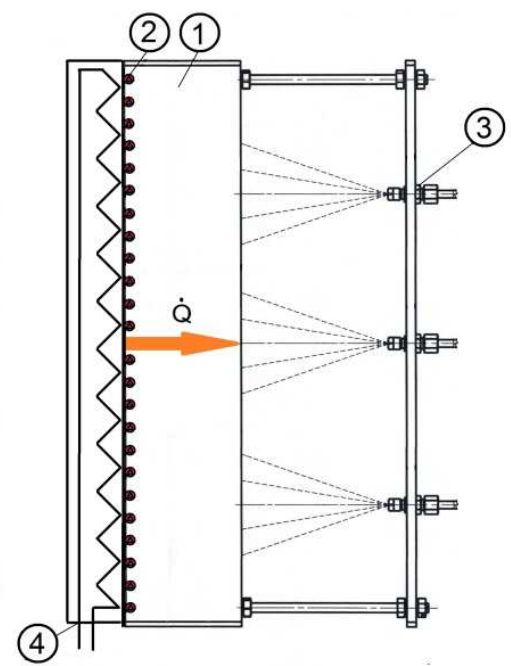

Rys. 1. Poglądowy schemat stanowiska: 1 - badany element grubościenny, 2 - termopara, 3 - dysza, 4 - grzałka elektryczna

Fig. 1. Test stand scheme: 1 - thick-walled tested element, $2-$ thermocouple, 3 - nozzle, 4 - electric heater 


\subsection{Płyta stalowa}

Głównym elementem stanowiska jest grubościenna płyta stalowa o wymiarach 800 × 800 x 85 mm wykonana ze stali P235GH (St36K). Stal ta wykorzystywana jest jako materiał konstrukcyjny takich urządzeń jak walczaki czy kolektory parowe. Właściwości cieplne i mechaniczne materiału płyty przedstawiono w tabeli 1.

Tabela 1. Właściwości mechaniczne i cieplne materiału płyty - stal konstrukcyjna P235GH (w temperaturze $20^{\circ} \mathrm{C}$ ).

Table 1. Mechanical and thermal properties of the plate material - P235GH constructional steel (in temperature of $20^{\circ} \mathrm{C}$ )

\begin{tabular}{|l|l|l|}
\hline \multicolumn{3}{|c|}{ Właściwości mechaniczne } \\
\hline Wytrzymałość na rozciąganie & $360-480$ & $\mathrm{~N} / \mathrm{mm}^{2}$ \\
\hline Granica plastyczności & 200 & $\mathrm{~N} / \mathrm{mm}^{2}$ \\
\hline Moduł Younga (E) Właściwości cieplne & $212 \cdot 10^{6}$ & $\mathrm{~N} / \mathrm{mm}^{2}$ \\
\hline \multicolumn{3}{|c|}{ ( } \\
\hline Współczynnik rozszerzalności cieplnej & $11,9 \cdot 10^{-6}$ & $\mathrm{~K}^{-1}$ \\
\hline Ciepło właściwe & 461 & $\mathrm{~J} /(\mathrm{kg} \cdot \mathrm{K})$ \\
\hline Przewodność cieplna & 57,5 & $\mathrm{~W} /(\mathrm{m} \cdot \mathrm{K})$ \\
\hline Gęstość & 785 & $\mathrm{~kg} / \mathrm{m}^{3}$ \\
\hline
\end{tabular}

Całkowity ciężar płyty wynosi ok. $430 \mathrm{~kg}$. Niezbędne jest zatem wykonanie konstrukcji nośnej zapewniającej odpowiednie ułożenie płyty w pozycji pionowej oraz montaż systemów: grzejnego i chłodzącego. Pomiar temperatury odbywać się będzie na powierzchni grzanej i chłodzonej oraz wewnątrz ściany płyty. Na powierzchni ogrzewanej rozmieszczono 41 punktów pomiaru temperatury (rys. 2). Termopary płaszczowe typu K (41 szt.) o średnicy płaszcza $\varnothing 1,5 \mathrm{~mm}$ zostaną umieszczone $\mathrm{w}$ specjalnie wyfrezowanych na powierzchni płyty rowkach o szerokości $1,5 \mathrm{~mm}$ i głębokości $2,0 \mathrm{~mm}$ Końcówki termopar będą dotykać materiału płyty tuż pod powierzchnią grzałki. Zapewni to bardziej dokładny pomiar temperatury, poprzez zmniejszenie oporu kontaktowego pomiędzy końcówką termopary a powierzchnią, której temperatura jest mierzona.

Na grubości płyty zostaną zamontowane cztery termopary. Licząc od powierzchni ogrzewanej, dwie termopary zostaną zainstalowane na głębokości równej $28,3 \mathrm{~mm}$ i po jednej termoparze na 56,7 i $82,0 \mathrm{~mm}$. W tych miejscach wykonywane będą gwintowane otwory, w które wkręcone zostaną specjalnie zaprojektowane śruby (rys. 3) z osadzonymi w ich wnętrzu termoparami, co zapewni bardzo dobry kontakt termopary i materiału, a więc przyczyni się do zwiększenia dokładności pomiaru. Śruby te posiadać będą otwór koncentryczny 
o odpowiednio ściętej końcówce, a montaż termopary w śrubie odbędzie się poprzez lutowanie.

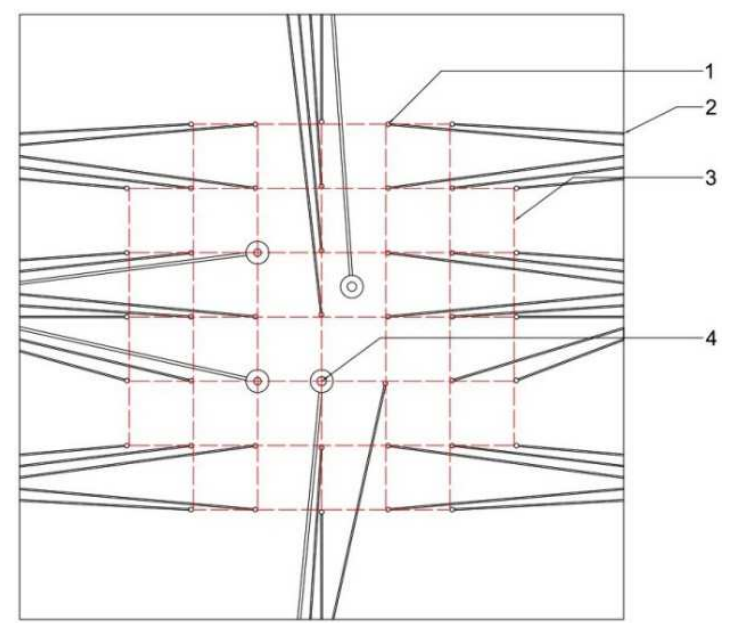

Rys. 2. Rozmieszczenie termopar wraz z rowkami (widok na ogrzewaną powierzchnię płyty): 1 - miejsce pomiaru temperatury na powierzchni płyty, 2 - rowek pod termoparę, 3 - siatka pomiarowa, 4 - miejsce pomiaru temperatury wewnątrz płyty

Fig. 2. Thermocouples arrangement scheme (view on the heated surface of the plate ): 1 - the temperature measurement place, 2 - the thermocouple groove, 3 - the measured grid, $4-$ the place of temperature measurement inside the plate

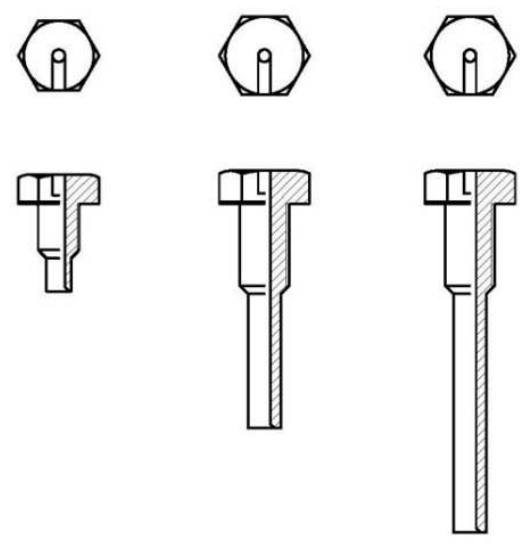

Rys. 3. Przekrój śrub stalowych wraz z umieszczeniem termopar do pomiaru temperatury wgłębnej płyty

Fig. 3. Steel bolts cross-section with thermocouples for the temperature measurement 
Ponieważ do powierzchni ogrzewanej przylega płaski element grzejny, termopary wyprowadzone będą na zewnątrz wykonanymi w płycie rowkami o szerokości 3,1 $\mathrm{mm}$ oraz głębokości 4,0 $\mathrm{mm}$. Do pomiarów temperatury wybrano termopary typu K o długości płaszcza $1000 \mathrm{~mm}$. Niewielka grubość termoelementów, poprzez bardzo małą wartość stałej masowej, wpłynie na szybsze wyznaczenie zmian temperatury mierzonej powierzchni w czasie. Średnica płaszcza termopar do pomiarów wgłębnych wynosić będzie $\varnothing 3,0 \mathrm{~mm}$. W celu orientacyjnego wyznaczenia temperatury strony ,zimnej” na powierzchni chłodzonej płyty umieszczona zostanie tylko jedna termopara.

W celu zbierania i gromadzenia danych pomiarowych wykorzystywano układ akwizycji danych (UAD) z 70 kanałami wejściowymi i o małym czasie skanowania termopar wynoszącym maksymalnie $1,1 \mathrm{~s}$. Zapewni to większą dokładność oraz pozwoli na zwiększenie rozdzielczości i szybkości wykonywanych pomiarów.

\subsection{Układ grzejny i chłodzący}

W koncepcji stanowiska założone zostało, iż płyta po stronie gorącej osiągnie maksymalną temperaturę równą $300^{\circ} \mathrm{C}$. W tym celu dobrany został płaski płytowy element grzejny o mocy $6 \mathrm{~kW}$ w postaci grzałki mikanitowej o wymiarach 600 x $600 \mathrm{~mm}$ i grubości $5 \mathrm{~mm}$. Zbudowana jest on z taśmy oporowej (element grzejny) zabudowanej w izolacji mikanitowej obleczonej z obu stron blachą nierdzewną o grubości $1 \mathrm{~mm}$. Prawidłowe przymocowanie grzałki do powierzchni (zapewniający idealny kontakt między powierzchniami) skutkować będzie równomiernym nagrzewaniem elementu. Zostanie ona przytwierdzona do płyty w czterech miejscach za pomocą połączeń śrubowych. Grzałka wyposażona jest $\mathrm{w}$ regulator temperatury $\mathrm{z}$ wbudowaną termoparą.

Układ chłodzenia zbudowany jest z 9 dysz rozmieszczonych równomiernie w przeźroczystej płycie z tworzywa sztucznego (Lexan) o wymiarach 600 x 600 i grubości $10 \mathrm{~mm}$. Dysze połączone są elastycznymi przewodami z kolektorem zbiorczym posiadającym możliwość przyłączenia odpowiedniego źródła chłodzenia, tj. zbiornika wody o pojemności 800 litrów lub kompresora powietrza. System zraszający zamontowany jest równoległe do zimnej powierzchni płyty i oddalony jest od niej o $20 \mathrm{~cm}$.

\subsection{Konstrukcja nośna stanowiska}

Ze względu na bardzo duży ciężar badanego elementu grubościennego (ok. $430 \mathrm{~kg}$ ) konieczne było zaprojektowanie i wykonanie odpowiedniej konstrukcji podtrzymującej. Przeprowadzone zostały obliczenia wytrzymałościowe pozwalające na wyznaczenie wymiarów całej konstrukcji nośnej. Zbudowana jest ona z dwuteowników i kątowników ze stali konstrukcyjnej. Rys. 4 przedstawia widok konstrukcji nośnej stanowiska. 
Płyta grubościenna będzie ustawiona pionowo i zostanie umieszczona w obudowie osłaniającej ją ze wszystkich stron, oprócz powierzchni chłodzonej, która może być odsłonięta. Obudowa będzie się składać wobec tego z dwóch części. Jedna z nich zamontowana będzie od strony gorącej, a druga od strony zimnej płyty (rys. 5).
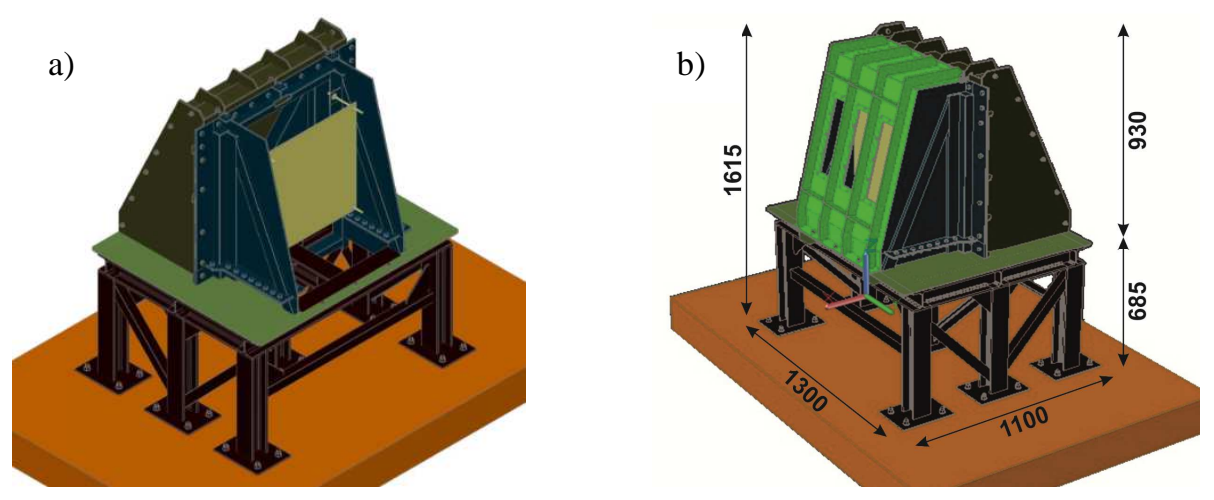

Rys. 4. Wizualizacja stanowisko badawczego - widok na stronę gorącą: a) bez obudowy; b) wymiary charakterystyczne stanowiska

Fig. 4. The test stand visualisation - the view on the hot site: a) without casing b) characteristic dimensions of the stand

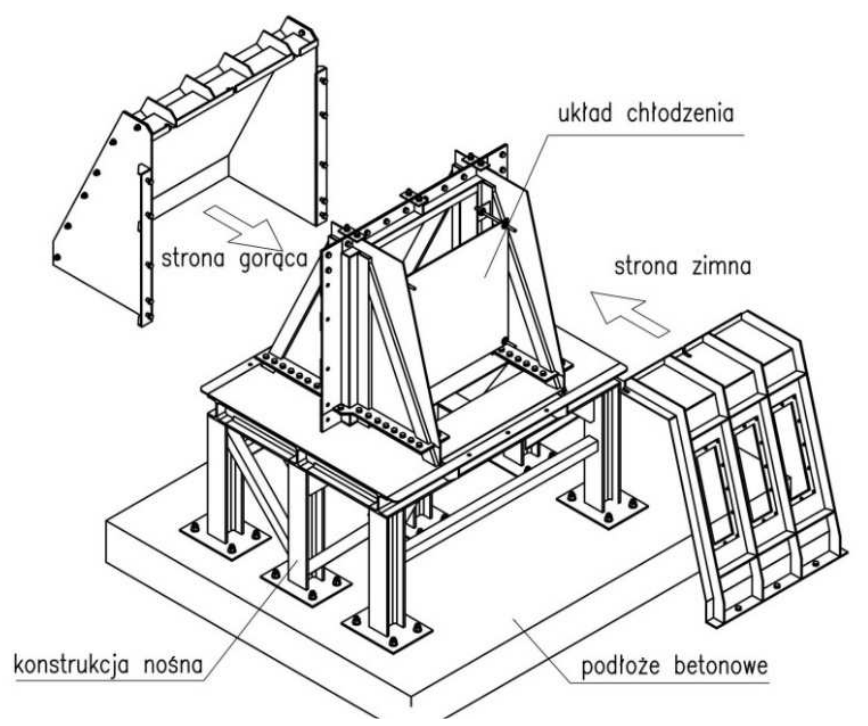

Rys. 5.Rysunek złożeniowy konstrukcji nośnej stanowiska badawczego

Fig. 5. Assembly drawing of supporting structure of the test stand 
Pomiędzy częścią obudowy od strony ogrzewanej a powierzchnią boczną płyty umieszczone zostanie uszczelnienie odporne na działanie wysokiej temperatury. Szczelność tej części obudowy zapewni bezpieczną pracę grzałki oraz termopar. Przestrzeń pomiędzy ogrzewaną płytą a szczelną obudową zostanie wypełniona wełną mineralną $\mathrm{w}$ celu minimalizacji strat ciepła do otoczenia i wymuszenia przepływu ciepła tylko na grubości płyty. Odprowadzenie wody chłodzącej przeprowadzone zostanie za pomocą odpowiednio zaprojektowanego blatu podłączonego do kanalizacji rurą DN 50.

\section{Podsumowanie}

Przedstawione w artykule stanowisko badawcze pozwoli na weryfikację doświadczalną opracowanej trójwymiarowej metody odwrotnej kroczącej, służącej do określania rozkładu temperatury w badanym elemencie grubościennym. Stanowisko budowane jest obecnie w Instytucie Maszyn i Urządzeń Energetycznych Politechniki Krakowskiej. Zakończenie prac konstrukcyjnych planowane jest na sierpień 2014.

\section{Literatura}

[1] Jaremkiewicz M.: Odwrotne zagadnienia wymiany ciepła występujące w pomiarach nieustalonej temperatury płynów, Politechnika Krakowska, Kraków 2011.

[2] Taler J., Jaremkiewicz M., Taler D., Sobota T.: Fluid temperature measurement under transient conditions, Arch. Thermodynamics, 30 (2009) 75-88.

[3] Jaremkiewicz M.: Wyznaczanie nieustalonej temperatury czynnika przy wykorzystaniu metod odwrotnych kroczących, Systemy, technologie i urządzenia energetyczne, praca zbiorowa pod red. J. Talera, Politechnika Krakowska, Kraków 2010.

Przedstawione $w$ artykule wyniki zostaty uzyskane $w$ badaniach wspótfinansowanych przez Narodowe Centrum Badań i Rozwoju w ramach umowy PBS1/A4/4/2012 Projekt Badań Stosowanych - Opracowanie nowoczesnych metod oceny trwatości resztkowej elementów ciśnieniowych instalacji energetycznych.

\section{THE LABORATORY STAND PROJECT FOR THE EXPERIMENTAL VERIFICATION OF DETERMINING METHOD OF THE TRANSIENT TEMPERATURE FIELD DISTRIBUTIONIN THICK-WALLED COMPONENTS}

\section{S u m m a r y}

The paper presents the design of laboratory stand to verify the method of determining threedimensional transient temperature field in thick-walled components. The key element of the laboratory stand is a plate made of P235GH steel with the dimensions of: $800 \times 800 \mathrm{~mm}$ and 
thickness of $85 \mathrm{~mm}$. Non-uniform temperature distribution in the tested element will be achieved by heating and cooling of opposite plate surfaces. As a part of the article the test stand design and its $3 \mathrm{D}$ visualisation have been presented. The design of the plate with the location of thermoelectric temperature measuring instrument and building the heating and cooling system has been described in detail.

Keywords: step inverse method, transient temperature field, laboratory stand, thick-walled elements, heat conduction

DOI: $10.7862 / \mathrm{rm} .2014 .6$

Otrzymano/received: 15.05.2014

Zaakceptowano/accepted: 7.06.2014 